\title{
PROPAGAÇÃO VEGETATIVA DE GENÓTIPOS DE PITANGUEIRA (Eugenia uniflora L.) DO SUL DO BRASIL POR ENXERTIA DE GARFAGEM ${ }^{1}$

\author{
RODRIGO CEZAR FRANZON², RAFAEL DA SILVA GONÇALVES ${ }^{3}$, \\ LUIS EDUARDO CORRÊA ANTUNES ${ }^{4}$, MARIA DO CARMO BASSOLS RASEIRA ${ }^{4}$
}

RESUMO - Este trabalho teve como objetivo avaliar o uso da enxertia de garfagem em fenda cheia na propagação vegetativa de diferentes genótipos de pitangueira. Foram utilizados sete genótipos do Banco Ativo de Germoplasma de fruteiras nativas do Sul do Brasil, mantidos na Embrapa Clima Temperado, em Pelotas-RS, dos quais foram coletados garfos (estacas semilenhosas), com aproximadamente $5 \mathrm{~cm}$ de comprimento. Utilizou-se como porta-enxertos de plantas de pitangueira oriundas de sementes. O diâmetro médio no ponto de enxertia foi de $2,5 \mathrm{~mm}$. A enxertia foi realizada em setembro de 2006 . O delineamento experimental foi o inteiramente casualizado, com quatro repetições, sendo a unidade experimental constituída por 10 plantas. Foram avaliadas as percentagens de brotação e de pegamento dos enxertos. Os percentuais de estacas brotadas variaram entre $45,0 \%$ e $95,0 \%$, enquanto o pegamento dos enxertos variou entre $40,0 \%$ e $87,5 \%$. Percentuais acima de $65,0 \%$ foram obtidos para as seleções "Pit 75 ", "Pit 61 " e "Pit 137", para ambos os parâmetros avaliados, brotação e pegamento dos enxertos. Existe diferença entre genótipos desta espécie quanto à capacidade de pegamento na enxertia por garfagem no topo em fenda cheia. Este tipo de enxertia é apropriado para a propagação vegetativa da pitangueira.

Termos para indexação: Myrtaceae, clonagem, propagação assexual, genótipo.

\section{VEGETATIVE PROPAGATION OF SURINAM CHERRY (Eugenia uniflora L.) GENOTYPES FROM SOUTHERN BRAZIL, THROUGH CLEFT GRAFT}

\begin{abstract}
This work had the objective of testing cleft grafting as a way to asexually propagate different genotypes of Surinam cherry. Bud woods of around $5 \mathrm{~cm}$ length were collected from seven genotypes of the Germplasm Bank of Embrapa Clima Temperado, Pelotas, RS. Seedling plants of Surinam cherry seedlings were used as rootstocks. The average diameter at the grafting point was $2.5 \mathrm{~mm}$. Grafting was done on September, 2006. The experiment was carried out as a completely randomized design with four replications and 10 plants per plot. Evaluations were based on percentages of sprouting and budding efficiency. Percentages of sprouting were between $45.0 \%$ and $95 \%$ whereas percentages of grafting success in obtain the desirable clones were among $40.0 \%$ to $87.5 \%$. Percentages above $65.0 \%$ for evaluated parameters, sprouting and grafting success were obtained in selections "Pit 75", "Pit 61" and "Pit 137". There were differences among genotypes for percentage of cleft grafting success in Surinam cherry propagation. This type of grafting is recommended for Surinam cherry vegetative propagation.
\end{abstract}

Index terms: Myrtaceae, clone, asexual propagation, genotype.

\footnotetext{
1(Trabalho 005-09). Recebido em: 05-01-2009. Aceito para publicação em: 03-04-2009. Apoio: FAPERGS, EMBRAPA Macro Programas.

${ }^{2}$ Eng. Agrônomo, Dr., Pesquisador Embrapa Cerrados, BR 020, Km 18, Caixa Postal 8223, Planaltina-DF. CEP: 73310-970. E-mail: rodrigo.franzon@cpac.embrapa.br

${ }^{3}$ Acadêmico do Curso de Graduação em Agronomia, Universidade Federal de Pelotas, Câmpus Universitário, s/nº , Pelotas-RS. CEP: 96010-900, Bolsista PET Agronomia/FAEM/UFPel. E-mail: rafaeldasilvagoncalves@gmail.com

${ }^{4}$ Eng. Agrônomo, Dr., Pesquisador Embrapa Clima Temperado, Rodovia BR 392, km 78, Pelotas-RS. CEP: 96001-970. antunes@cpact.embrapa.br, bassols@cpact.embrapa.br; (Bolsista PQ/CNPq).
} 


\section{INTRODUÇÃO}

A pitangueira (Eugenia uniflora L.) tem origem na região que se estende desde o Brasil Central até o norte da Argentina, estando distribuída por quase todo o território brasileiro, e em outras partes do mundo (Bezerra et al., 2000; Donadio et al., 2002). Esta espécie, devido às características de seus frutos, de sabor exótico e rico em vitaminas, apresenta grande potencial para exploração econômica.

No Nordeste brasileiro, genótipos com elevado potencial produtivo e boas características agronômicas vêm sendo selecionados pela Empresa Pernambucana de Pesquisa Agropecuária - IPA (Bezerra et al., 1995; 1999). Os trabalhos de seleção resultaram no lançamento da primeira cultivar brasileira de pitangueira, denominada "Tropicana" (Bezerra et al., 2004; 2008).

No Sul do Brasil, a Embrapa Clima Temperado, em Pelotas-RS, vem realizando estudos agronômicos com algumas fruteiras nativas da região, dentre as quais a pitangueira. Esta é uma das espécies estudadas que apresenta, a curto prazo, maior potencial para cultivo na região, pois existem trabalhos adiantados de seleção de clones (Franzon et al., 2004). Atualmente, existem em torno de 150 genótipos, dentre os quais muitos poderiam ser testados para verificar as possibilidades de serem propagados como cultivares comerciais.

Porém, um dos maiores problemas encontrados para viabilizar a exploração econômica desta espécie é a produção de mudas. No Brasil, existem áreas de plantio comercial no Estado do Pernambuco, onde a importância econômica da espécie vem crescendo (Bezerra et al., 1999, 2002; Lira Júnior et al., 2007; Bezzerra et al., 2008). Entretanto, de acordo com estes mesmos autores, a pitangueira não possui expressão econômica no contexto da fruticultura nacional, e os plantios são realizados exclusivamente com mudas de pé-franco, originadas a partir de sementes. Deste modo, para maiores avanços na expansão do cultivo, é necessário encontrar alternativas viáveis para a propagação vegetativa.

A propagação por sementes apresenta como inconvenientes a grande variabilidade entre as plantas e também na produção, frutificação baixa e mais tardia, baixa qualidade de frutos, entre outros. Por outro lado, a propagação clonal proporciona a formação de pomares uniformes, com populações de plantas homogêneas.

No Nordeste brasileiro, alguns trabalhos com propagação vegetativa da pitangueira foram conduzidos no Estado de Pernambuco (Bezerra et al., 1999; 2002). Estes autores recomendam a utilização da enxertia por garfagem, devido ao menor tempo para a formação da muda. No entanto, a prática da enxertia na pitangueira ainda é pouco conhecida dos viveiristas e produtores daquela região. Mais recentemente, Franzon et al. (2008) utilizaram este mesmo método de enxertia, porém com diâmetro de porta-enxerto e enxerto mais reduzidos, na propagação vegetativa desta espécie no Sul do Brasil. Os resultados foram promissores, com percentuais de pegamento de até $67,5 \%$, sendo a saída do inverno, na primeira quinzena do mês de setembro, a época mais adequada para a realização da enxertia naquela região.

Deste modo, o objetivo do trabalho foi o de avaliar o uso da enxertia por garfagem no topo em fenda cheia, na propagação de diferentes genótipos de pitangueira existentes na Embrapa Clima Temperado.

\section{MATERIAL E MÉTODOS}

O experimento foi conduzido na Embrapa Clima Temperado, em Pelotas-RS (31 ${ }^{\circ} 40^{\prime} 47^{\prime}$ 'S e $52^{\circ} 26^{\prime} 24^{\prime \prime} \mathrm{W}$; $60 \mathrm{~m}$ de altitude), no ano de 2006. Foram testados sete genótipos quanto à capacidade de propagação através da enxertia: "Pit 15", "Pit 61", "Pit 74", "Pit 75", "Pit 77", "Pit 137” e "Pit 161", pertencentes ao Banco Ativo de Germoplasma de fruteiras nativas do Sul do Brasil, mantido na Embrapa Clima Temperado.

Os garfos foram coletados de ramos semilenhosos oriundos do ciclo de crescimento anterior (setembro de 2005 a maio de 2006). Para a obtenção de maior número de ramos que pudessem ser utilizados para a coleta de garfos, foi realizada uma poda drástica em galhos das plantas-mãe, em setembro de 2005, a fim de estimular a emissão de novas brotações. Os garfos foram coletados pela manhã, de plantas adultas, sendo que a enxertia foi realizada logo após a coleta. Para transporte do material vegetal do campo até o local da enxertia, o mesmo foi mantido em recipiente, com a base dos ramos imersa em água, a fim de evitar desidratação. Foram utilizados garfos com tamanho aproximado de $5 \mathrm{~cm}$ de comprimento, com diâmetro o mais próximo possível ao diâmetro do porta-enxerto, e com um par de gemas, nos quais foram mantidas as duas folhas, cada uma delas reduzida em $50 \%$ de sua área foliar. Ressalta-se que, mesmo nas condições de inverno da região Sul do Brasil, as plantas de pitangueira não perdem suas folhas. Também, foram mantidas as folhas existentes no porta-enxerto, abaixo do ponto de enxertia, a fim de manter a atividade fotossintética da planta até que houvesse a união dos tecidos do porta-enxerto e do garfo. Diferentemente, as brotações laterais 
existentes nesta região foram eliminadas, bem como aquelas que surgiram durante o acompanhamento do experimento.

Foram utilizadas, como porta-enxertos, plantas provenientes de sementes coletadas de plantas de pitangueira, escolhidas aleatoriamente, na Embrapa Clima Temperado. Estas foram semeadas em sacolas plásticas de coloração preta, medindo $8 \mathrm{~cm}$ de diâmetro e $15 \mathrm{~cm}$ de altura, contendo como substrato terra misturada com areia, na proporção de 3:1.

Os porta-enxertos foram mantidos em condições ambientais, sob telado. No dia da enxertia, foram levados para casa de vegetação. Foi realizada a enxertia de garfagem no topo em fenda cheia, a uma altura entre 30 e $40 \mathrm{~cm}$ do colo da planta, no dia 06 de setembro de 2006. No momento da enxertia, os porta-enxertos apresentavam um diâmetro médio no ponto de enxertia de $2,5 \mathrm{~mm}$. A enxertia foi realizada com o auxílio de bisturi, pois, para um perfeito contato entre as partes, torna-se necessário um corte uniforme. A amarração foi realizada com fita biodegradável para enxertia.

Após a realização da enxertia, o enxerto (porta-enxerto + garfo) foi coberto com um saco plástico transparente tipo celofane $(18 \mathrm{~cm} \times 30 \mathrm{~cm})$, a fim de formar uma câmara úmida para evitar a desidratação dos tecidos e nele se fez um corte de 2 $\mathrm{cm}$ em uma das pontas superiores. $\mathrm{O}$ saco plástico foi amarrado a uma distância de 15 a $20 \mathrm{~cm}$ abaixo do ponto de enxertia. As plantas foram mantidas em casa de vegetação.

O delineamento foi o inteiramente casualizado, com quatro repetições, sendo a unidade experimental constituída por 10 plantas. Foram observadas as percentagens médias de brotação e de pegamento dos enxertos. Os experimentos foram acompanhados semanalmente e foram considerados brotados aqueles que apresentavam brotações com início de expansão do primeiro par de folhas. Neste momento, também foi feita a retirada dos sacos plásticos. A percentagem final de pegamento dos enxertos foi avaliada entre os 100 e 110 dias após a instalação dos experimentos, considerando-se apenas os enxertos sobreviventes.

Os resultados obtidos foram submetidos à análise de variância e comparação de médias, pelo teste de Scott-Knott $(p \leq 0,05)$. As análises foram realizadas com o programa SISVAR (Ferreira, 2000). Os dados obtidos, número de enxertos brotados e número de pegamento de enxertos, foram transformados para $\sqrt{\mathrm{x}+0,5}$ antes da análise estatística.

\section{RESULTADOS E DISCUSSÃO}

Houve diferenças estatísticas significativas para os percentuais de enxertos brotados e pegamento de enxertos entre as diferentes seleções testadas. Os percentuais de pegamento de enxertos variaram entre $40,0 \%$ e $87,5 \%$. Percentuais acima de $65 \%$ foram obtidos para as seleções "Pit 75", "Pit 61" e "Pit 137”, tanto para brotação quanto para pegamento dos enxertos (Tabela 1).

As diferenças observadas entre os genótipos quanto ao pegamento dos enxertos podem estar relacionadas com diversos aspectos. O mais importante é o fator genético, uma vez que diferentes genótipos podem responder de forma diferente quanto à capacidade de propagação vegetativa, seja por enxertia, seja mesmo por outro método, como, por exemplo, a estaquia. Outro fator pode ser a diferença entre o estádio de desenvolvimento dos garfos entre os diferentes genótipos testados, e também em relação ao porta-enxerto, uma vez que existe grande variação entre genótipos no que diz respeito à brotação e ao crescimento dos ramos. Pequenas diferenças na resposta de crescimento após a realização da poda podem ocasionar diferenças no pegamento de enxertos, pois algumas seleções poderiam apresentar ramos mais lignificados do que outras, o que pode favorecer ou prejudicar o sucesso na enxertia.

Os percentuais de pegamento de enxertos de pitangueira obtidos neste trabalho são semelhantes aos resultados de Bezerra et al. (2002), os quais testaram 10 genótipos desta espécie no Nordeste brasileiro, com percentuais de pegamento variando entre $20,0 \%$ e $81,5 \%$. Estes autores relatam que, possivelmente, os menores percentuais observados em alguns genótipos sejam decorrentes de problemas de compatibilidade entre enxerto e porta-enxerto, uma vez que a compatibilidade é função de afinidade fisiológica e anatômica. A primeira diz respeito à região da enxertia, que pode tornar-se seletiva, podendo dificultar o transporte de seiva entre as partes. Já a segunda estaria relacionada com a íntima associação dos tecidos cambiais na formação da conexão, a qual pode ser comprometida quando a copa e o porta-enxerto possuírem células diferentes quanto ao tamanho, forma e consistência.

Fachinello et al. (2005) reportam que, quanto maior for a afinidade entre enxerto e porta-enxerto, maior a probabilidade de sucesso na enxertia. Assim, a diferença nos percentuais de pegamento de enxertos entre as diferentes seleções pode estar sendo influenciada pelos dois tipos de incompatibilidade, seja pelo fato de as diferentes seleções apresentarem diferenças fisiológicas, uma vez que estas podem 
responder de forma diferente às condições ambientais, seja por diferenças em relação ao porta-enxerto. Também, pode estar sendo influenciada por diferenças anatômicas entre as partes envolvidas, conforme discutido no parágrafo anterior.

Em relação aos porta-enxertos, a propagação é feita exclusivamente por sementes, pois não existe um método eficiente de propagação vegetativa para esta espécie. Conforme já mencionado, a variabilidade destes seedlings (mudas produzidas por sementes) é grande. Se pensarmos na propagação vegetativa de cultivares para cultivo comercial, isto poderá representar um problema. A propagação vegetativa por estacas pode ser uma solução. Alguns trabalhos com propagação vegetativa de Mirtáceas produtoras de frutos são encontrados na literatura (Leonel et al., 1991; Coutinho et al., 1992; Duarte et al., 1992; Figueiredo et al., 1995; Scarpare Filho et al., 1999; Franzon et al., 2004), porém os percentuais de enraizamento na estaquia convencional não são nada satisfatórios para espécies frutíferas desta família.

Valores de pegamento de enxertia próximos aos encontrados no presente trabalho foram obtidos também por Bezerra et al. (1999), em Pernambuco, que obtiveram percentuais de até 77,5\%, e por Franzon et al. (2008), em Pelotas-RS, com percentuais de até $67,5 \%$. Estes autores utilizaram a enxertia de garfagem no topo em fenda cheia ou dupla fenda e, em ambos os trabalhos, os melhores resultados foram obtidos com a garfagem em fenda cheia, o que indica que este método de enxertia, utilizado no presente trabalho, é adequado para a propagação vegetativa da pitangueira.

Pequenas diferenças entre as percentagens de brotação e de pegamento dos enxertos foram observadas (Tabela 1). O mesmo foi observado por Franzon et al. (2008). Isto se deve, provavelmente, porque o enxerto possui reservas suficientes para iniciar a brotação. Porém, a não formação da união entre os tecidos do enxerto com os do porta-enxerto e, consequentemente, a não formação dos vasos condutores de seiva causaram a morte desta brotação.

Os resultados obtidos no presente trabalho, nas condições de Pelotas-RS, associados aos resultados obtidos em trabalhos anteriores nesta mesma região (Franzon et al., 2008), e aos obtidos por Bezerra et al. (1999, 2002), em Pernambuco, demonstram que a enxertia de garfagem no topo pode ser utilizada na produção de mudas de pitangueira de alta qualidade. Assim, abrem-se novas perspectivas para trabalhos com essa fruteira nativa nas diferentes regiões do País. Com esta alternativa, em breve, algumas seleções mantidas na Embrapa Clima Temperado poderão ser testadas para serem propagadas como cultivares.

TABELA 1 - Percentagem de brotação e pegamento dos enxertos de sete seleções de pitangueira (Eugenia uniflora), utilizando-se da enxertia de garfagem no topo em fenda cheia, na saída do inverno, em Pelotas-RS.

\begin{tabular}{lcc}
\hline Seleção & Brotação (\%) & Pegamento (\%) * \\
\hline Pit 75 & $95,0 \mathrm{a}$ & $87,5 \mathrm{a}$ \\
Pit 61 & $82,5 \mathrm{a}$ & $75,0 \mathrm{a}$ \\
Pit 137 & $65,0 \mathrm{a}$ & $65,0 \mathrm{a}$ \\
Pit 74 & $45,0 \mathrm{~b}$ & $45,0 \mathrm{~b}$ \\
Pit 77 & $45,0 \mathrm{~b}$ & $45,0 \mathrm{~b}$ \\
Pit 15 & $47,5 \mathrm{~b}$ & $45,0 \mathrm{~b}$ \\
Pit 161 & $50,0 \mathrm{~b}$ & $40,0 \mathrm{~b}$ \\
\hline Média geral & 61,43 & 57,50 \\
\hline CV (\%) & 12,06 & 13,99 \\
\hline
\end{tabular}

* Médias seguidas por letras minúsculas distintas na coluna diferem estatisticamente entre si, pelo teste de Scott-Knott ( $p \leq 0,05)$. Para análise estatística, foram utilizados os dados de número de enxertos brotados e de pegamento dos enxertos, os quais foram transformados segundo a equação $\sqrt{\mathrm{x}+0,5}$.

$\mathrm{CV}=$ coeficiente de variação. 


\section{CONCLUSÕES}

1- Existe diferença entre genótipos desta espécie quanto à capacidade de pegamento na enxertia de garfagem no topo em fenda cheia.

2- A enxertia de garfagem no topo em fenda cheia, na saída do inverno, é indicada para ser utilizada na propagação vegetativa da pitangueira, no Sul do Brasil.

\section{REFERÊNCIAS}

BEZERRA, J.E.F.; LEDERMAN, I.E.; FREITAS, E.V. da; SANTOS, V.F. dos. Método de enxertia e idade de porta-enxerto na propagação da pitangueira (Eugenia uniflora L.). Revista Brasileira de Fruticultura, Jaboticabal, v.21, n.3, p.262-265, 1999.

BEZERRA, J.E.F.; LEDERMAN, I.E.; FREITAS, E.V. da; SILVA JUNIOR, J.F. da. Propagação de genótipos de pitangueira (Eugenia uniflora L.) pelo método de enxertia de garfagem no topo em fenda cheia. Revista Brasileira de Fruticultura, Jaboticabal, v.24, n.1, p.160-162, 2002.

BEZERRA, J.E.F.; LEDERMAN, I.E.; PEDROSA, A.C.; DANTAS, A.P.; FREITAS, E.V. de. Performance of surinam cherry (Eugenia uniflora L.) in Pernambuco, Brazil. Acta Horticulturae, Vitória, n.370, p.77-81, 1995.

BEZERRA, J.E.F.; LEDERMAN, I.E.; SILVA JUNIOR, J.F. da.; ALVES, M.A. Comportamento da pitangueira (Eugenia uniflora L.) sob irrigação na região do Vale do Rio Moxotó, Pernambuco. Revista Brasileira de Fruticultura, Jaboticabal, v.26, n.1, p.177-179, 2004.

BEZERRA, J.E.F.; SILVA JUNIOR, J.F.; LEDERMAN, I.E. Melhoramento genético e o manejo da pitangueira em Pernambuco. In: SIMPÓSIO NACIONAL DO MORANGO, 4., ENCONTRO DE PEQUENAS FRUTAS E FRUTAS NATIVAS DO MERCOSUL, 3., 2008, Pelotas. Palestras \& Resumos...Pelotas: Embrapa Clima Temperado, 2008. p. 85-93.

BEZERRA, J.E.F.; SILVA JUNIOR, J.F. da; LEDERMAN, I.E. Pitanga (Eugenia uniflora L.). Jaboticabal: FUNEP, 2000. 30p. (Série Frutas Nativas, 1).
COUTINHO, E.F.; KLUGE, R.A.; JORGE, R.O. Efeito do ácido indolbutírico e antioxidante na formação de calos em estacas semilenhosas de goiabeira-serrana. Revista Brasileira de Fruticultura, Jaboticabal, v.14, n.3, p.141-143, 1992.

DONADIO, L.C.; MÔRO, F.V.; SERVIDONE, A.A Frutas brasileiras. Jaboticabal: Novos Talentos, 2002. 288p.

DUARTE, O.R.; FACHINELLO, J.C.; SANTOS FILHO, B.G. Multiplicação da goiabeira serrana através de estacas semilenhosas. Pesquisa Agropecuária Brasileira, Brasília, v.27, n.3, p.513-516, 1992.

FACHINELLO, J.C.; HOFFMANN, A.; NACHTIGAL, J.C. Propagação de plantas frutíferas. Brasília: Embrapa Informação Tecnológica, 2005. 221p.

FERREIRA, D.F. Manual do sistema SISVAR para análises estatísticas. Lavras: UFLA, 2000. 66p.

FIGUEIREDO, S.L.B.; KERSTEN, E.; SCHUCH, M.W. Efeito do estiolamento parcial e do ácido indolbutírico (IBA) no enraizamento de estacas de ramos de goiabeira-serrana (Feijoa sellowiana, Berg). Scientia Agrícola, Piracicaba, v.52, n.1, p.167-171, 1995.

FRANZON, R.C.; ANTUNES, L.E.C.; RASEIRA, M.C.B. Efeito do AIB e de diferentes tipos de estaca na propagação vegetativa da goiabeira-serrana (Acca selowiana Berg.). Revista Brasileira de Agrociência, Pelotas, v.10, n.4, p.515-518, 2004.

FRANZON, RC.; GONÇALVES, R. da S.; ANTUNES, L.E.C.; RASEIRA, M. do C.B.; TREVISAN, R. Propagação da pitangueira através da enxertia de garfagem. Revista Brasileira de Fruticultura, Jaboticabal, v.30, n.2, p.488-491, 2008.

FRANZON, RC.; RASEIRA, M.C.B.; CORREAA, E.R. Potencialidades agronômicas de algumas mirtáceas frutíferas nativas do Sul do Brasil. In: RASEIRA, M.C.B.; ANTUNES, L.E.C.; TREVISAN, R.; GONÇALVES, E.D. Espécies frutíferas nativas do sul do Brasil. Pelotas: Embrapa Clima Temperado, 2004. p.99-106. (Documentos, 129) 
LEONEL, S.; VARASQUIM, L.T.; RODRIGUES, J.D. Efeito da aplicação de fitorreguladores e ácido bórico em estacas de jabuticabeira (Myrciaria cauliflora Berg.). Revista Brasileira de Fruticultura, Jaboticabal, v.13, n.3, p.219-222, 1991.

LIRA JÚNIOR, J. S.; BEZERRA, J. E. F.; LEDERMAN, I. E.; SILVA JÚNIOR, J. F. Pitangueira. Recife: Liceu, 2007. 87p.
SCARPARE FILHO, J.A.; TESSAROLI NETO, J.; COSTA JÚNIOR, H. Efeito do ácido indolbutírico no enraizamento de estacas herbáceas de jabuticabeira 'Sabará' (Myrciaria jabuticaba) em condições de nebulização. Revista Brasileira de Fruticultura, Jaboticabal, v.21, n.2, p.146-149, 1999. 